\title{
Gas exchanges in children with cystic fibrosis or primary ciliary dyskinesia: a retrospective study
}

Marilyn Fuger ${ }^{\mathrm{a}}$ marilyn.fuger@aphp.fr, Camille Aupiais ${ }^{\mathrm{b}, \mathrm{c}, \mathrm{d}}$ camille.aupiais@aphp.fr, Guillaume Thouvenin ${ }^{\mathrm{e}, \mathrm{f}}$ guillaume.thouvenin@aphp.fr, Jessica Taytard ${ }^{\mathrm{e}, \mathrm{f}}$ jessica.taytard@aphp.fr, Aline Tamalet ${ }^{\mathrm{e}}$ aline.tamalet@cegetel.net, Estelle Escudier ${ }^{\mathrm{g}, \mathrm{h}}$ estelle.escudier@aphp.fr, Priscilla Boizeau ${ }^{\text {b,c }}$ priscilla.boizeau@aphp.fr, Harriet Corvol $^{\mathrm{e}, \mathrm{f}}$ harriet.corvol@aphp.fr, Nicole Beydon ${ }^{\mathrm{a}, \mathrm{f} *}$ nicole.beydon@aphp.fr

a AP-HP, Unité d’Exploration Fonctionnelle Respiratoire, Hôpital Armand-Trousseau, Paris, France

b AP-HP, Unité d’Epidémiologie Clinique, Hôpital Robert Debré, Paris, France

c Université Paris Diderot, Sorbonne Paris-Cité, INSERM U1123 et CIC-EC 1426, Paris, France

d INSERM U1138, Equipe 22, Sciences de l'information au service de la médecine personnalisée, Paris, France

e AP-HP, Service de Pneumologie pédiatrique, Centre National de Référence des Maladies Respiratoires Rares, Hôpital Trousseau, Paris, France

${ }^{\text {f }}$ Sorbonne Universités, UPMC Univ Paris 06, INSERM, Centre de Recherche SaintAntoine (CRSA), Paris France

g Sorbonne Universités, UPMC Univ Paris 06, INSERM UMR_S933, Paris, France

${ }^{\text {h }}$ AP-HP, Service de génétique et d'embryologie médicales, Hôpital Trousseau, Paris, France

* Correspondence to Dr Nicole Beydon, Unité Fonctionnelle de PhysiologieExplorations Fonctionnelles Respiratoires (EFR), Hôpital Armand-Trousseau 26 Avenue du Docteur Arnold Netter, 75571 Paris Cedex 12, France.

Phone: +33 144736332

Fax: +33 144736336

E-mail: nicole.beydon@trs.aphp.fr 


\begin{abstract}
Primary ciliary dyskinesia (PCD) and cystic fibrosis (CF) both entail bronchiectasis and pulmonary impairment as measured using spirometry, during childhood. We aimed at looking whether blood gas exchanges progressed differently between CF and PCD children in a retrospective study of repeated measurements. Comparisons between groups (Wilcoxon-Mann-Whitney and Chi-squared tests) and a mixed linear model, adjusted for age, evaluated associations between diseases and $\mathrm{PaO}_{2}, \mathrm{PaCO}_{2}$, or $\mathrm{PaO}_{2}-\mathrm{PaCO}_{2}$ ratio.
\end{abstract}

Among 42 PCD and 73 CF children, 62\% and 59\% had respectively bronchiectasis $(P=0.75)$. Spirometry and blood gases were similar at inclusion $\left(\mathrm{PaO}_{2}\right.$ median [IQR] PCD -1.80 [-3.40;-0.40]; CF -1.80 [-4.20;0.60] z-scores; $P=0.72) . \mathrm{PaO}_{2}$ and $\mathrm{PaO}_{2}$ $\mathrm{PaCO}_{2}$ ratio similarly and significantly decreased with age in both groups $(P<0.01)$ whereas $\mathrm{PaCO}_{2}$ increased more in $\mathrm{CF}(P=0.02)$ remaining within the range of normal (except for one child).

To conclude, gas exchange characteristics, similarly initially impaired in PCD and CF children, tended to less deteriorate with time in PCD children who could benefit from an early diagnosis.

Keywords: Primary Ciliary Dyskinesia, Clinical Aspects of Cystic Fibrosis, Pulmonary Gas Exchange, Childhood Respiratory Disease 


\section{Introduction}

Cystic fibrosis (CF) and primary ciliary dyskinesia (PCD) diseases show similarities as they both involve congenital impairment of mucociliary clearance leading to recurrent or chronic rhinosinusitis, airway infection, and bronchiectasis at paediatric age (Knowles and Boucher, 2002). Studies conducted in PCD or CF patients showed close lung function (LF) impairment as measured by static pulmonary volumes (Kraemer et al., 2006, Pifferi et al., 2012), forced expiratory volumes and flows (Magnin et al., 2012, Ren et al., 2008) and ventilation inhomogeneity assessed using the lung clearance index (LCI) with different study protocols (Aurora et al., 2005, Green et al., 2012, Kraemer et al., 2005). However, the latter index was correlated to Forced Expiratory Volume in $1 \mathrm{~s}\left(\mathrm{FEV}_{1}\right)$ in $\mathrm{CF}$ but not PCD in adolescents and adults, where Forced Expiratory Flows between $25 \%$ and $75 \%$ of FVC (FEF $25 \%-75 \%)$ were significantly correlated with LCI in both populations (Irving et al., 2013). FEV 1 is the most frequently used index to evaluate the severity of PCD and CF respiratory disease even though its relevance might differ between these two diseases. In CF patients, $\mathrm{FEV}_{1}$ was one of the characteristics significantly related to the clinical outcome, including survival (Kerem et al., 2014, Konstan et al., 2007, Liou et al., 2001) whereas the correlation between $\mathrm{FEV}_{1}$ and future symptoms seemed weaker in PCD children (Ellerman and Bisgaard, 1997, Hellinckx et al., 1998, Marthin et al., 2010). In addition to the presence of ventilation heterogeneity measured by LCI impairment, the deficit in respiratory Nitric Oxide (NO) production could further alter ventilation-to-perfusion ratios in these diseases. NO acts in the lung (among other effects) as an aerocrine messenger with vasodilator effect increasing $\mathrm{PaO}_{2}$ in patients with respiratory distress or in healthy subjects (Lundberg et al., 1996a, Lundberg et al.; 1996b). The nasal production of NO was measured low in PCD and CF subjects 
but lower in PCD subjects (Marthin et al., 2011). Moreover, despite a similar total level of orally exhaled NO, PCD patients exhibited lower NO bronchial output and alveolar concentration than healthy subjects, whereas CF patients had only a decrease in NO alveolar concentration (Walker et al., 2013). Finally, unlike CF, PCD first hits lower lung territories where a majority of gas exchanges takes place (CohenCymberknoh et al., 2014), supporting the hypothesis of dissimilar gas exchanges progression in PCD and CF children (the latter experiencing initially apical lesions). In CF children, partial pressure of Oxygen $\left(\mathrm{PaO}_{2}\right)$ steeply decreased in parallel to (but earlier than) $\mathrm{FEV}_{1}$ reaching low level in school age children while $\mathrm{PaCO}_{2}$ slightly increased from low to normal level (Kraemer et al., 2009). In PCD children, $\mathrm{PaO}_{2}$ also significantly decreased with age and could be altered in school age children but $\mathrm{PaCO}_{2}$ remained stable or slightly increased without association with age (Magnin et al., 2012).

We hypothesized that, independently of central airway impairment, ventilationperfusion mismatch would start earlier in PCD than in CF children and would worsen quicker in CF children. The demonstration of earlier lung impairment with gentler progression in PCD children compared to CF children would promote the importance of an early diagnosis in PCD in order to limit lung damages.

Our objective was to compare the evolution of gas exchange characteristics, i.e. $\mathrm{PaO}_{2}, \mathrm{PaCO}_{2}$ and $\mathrm{PaO}_{2}-\mathrm{PaCO}_{2}$ ratio, as a marker of ventilation/perfusion mismatch in CF and PCD children from 4 to 18 years of age. We also compared characteristics, respiratory history and other LF indexes between CF and PCD children.

\section{Methods}

\subsection{Subjects}


Children were recruited from monocenter retrospective cohorts in the National Centre for Respiratory Rare Disease and the Paediatric Cystic Fibrosis Centre of Trousseau Hospital (Paris, France). Data recording started in 2000 up to 2015. Diagnosis retained was CF for children with causal CF mutations and/or positive sweat tests and PCD for children with sino-pulmonary syndrome and situs inversus (i.e. Kartagener syndrome), or suggestive clinical features and typical abnormal ciliary ultrastructure, or causal biallelic mutations in a known PCD gene. In all children, immunodeficiency was excluded as well as diseases which could alter $\mathrm{PaO}_{2}$ (e.g. heart disease with shunt, scoliosis, obesity, airway malacia). Pancreatic sufficient CF children were secondarily excluded because these children are known to have milder respiratory disease and there were too few of them $(n=8)$ to allow statistical analysis. Bronchiectasis was diagnosed from a standardised computed tomography performed in all PCD children at diagnosis or before depending on lower respiratory symptoms, and in CF children at 5 years of age or before depending on lower respiratory symptoms. Bronchiectasis was confirmed when bronchoarterial ratio was over 1 , or when bronchus lacked tapering or were visualised within $1 \mathrm{~cm}$ of pleural surface.

We looked for all LFTs including $\mathrm{PaO}_{2}$ measurements and excluded results obtained during acute airway infection or respiratory exacerbation (i.e. change in treatment because of respiratory symptoms during the previous week), or showing a significant bronchodilator response as $\mathrm{PaO}_{2}$ was measured before bronchodilator administration. It is to be noted that in our laboratory, blood gas analyses considered as unreliable are not recorded, and therefore were not available for the present study. Routine criteria for blood gas unreliability and, therefore, non-inclusion were: only one capillary sampled; between-capillary $\mathrm{PaO}_{2}$ difference larger than 1 Standard Deviation (5 mmHg (Gaultier et al., 1979)); child with obvious altered breathing pattern (usually 
because of cry). Eligible children were included at the time of their first $\mathrm{PaO}_{2}$ measurement available (cross-sectional study), then all subsequent LFT including blood gas analysis performed in stable conditions were recorded (longitudinal study).

\subsection{Lung function measurements}

Ear lobe capillary blood gas was performed as previously described in our laboratory (Gaultier et al., 1979). The mean of 2 to 4 capillary results was recorded. Lung function results from children able to perform lung volumes and forced expiratory volumes and flows measurements (Masterscreen, Vyair Medical, CareFusion, Adhésia, France, or BodyBox, Medisoft, Belgium) according to international recommendations were recorded (Beydon et al., 2007, Miller et al., 2005, Wanger et al., 2005). We used the database e-RespiRare ${ }^{\circledR}$ software national register (elaborated by UMR_S707 and 719, INSERM) to record clinical, microbiological, and therapeutic features.

Children over 8 years of age and their parents gave their consents to perform investigations; the ethical review board of the National Centre approved the retrospective use of the database register on 20/03/2008 (CCTIRS, no.08.015bis).

\subsection{Statistical Analysis}

This study conducted in children with rare respiratory diseases was not based on a power calculation but on the feasibility to retrospectively include repeated $\mathrm{PaO}_{2}$ measurements from our national register of Rare Respiratory Diseases. Quantitative variables were expressed in median and interquartile range [IQR], range and percentage when appropriate. Chi2 or Fisher's exact tests were applied to compare qualitative data and Wilcoxon's test to quantitative data. Anthropometric measures and lung function indexes, including $\mathrm{PaO}_{2}$ and $\mathrm{PaCO}_{2}$, were expressed or as z-scores 
(standard deviations from the mean) (Gaultier et al., 1979, Quanjer et al., 2012, Rolland-Cachera et al., 1991, Stocks and Quanjer, 1995). To take into account repeated measures in individuals, the effect of the disease on $\mathrm{PaO}_{2}, \mathrm{PaCO}_{2}$ and $\mathrm{PaCO}_{2}-\mathrm{PaCO}_{2}$ ratio was studied using a random-intercept mixed model, adjusted for age. Further bivariate analyses assessed the association of the following covariates with $\mathrm{PaO}_{2}$ (as, in contrast to $\mathrm{PaCO}_{2}, \mathrm{PaO}_{2}$ was altered in more than one children): sex, Body Mass Index (BMI), Forced Expiratory Capacity (FVC), FEV $1, \mathrm{FEV}_{1} / \mathrm{FVC}$

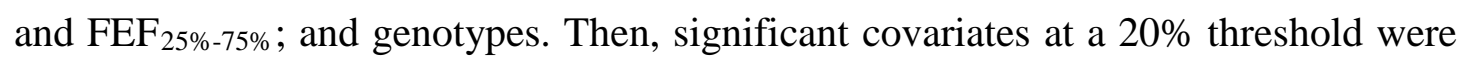
retained in two final multivariate models (one including FVC and the second FEV 1 because they were collinear variables). The $P$-value confirmed a statistical relationship when $<0.05$ (two-sided). All analyses were performed using the statistical software (V.9.4; SAS institute).

\section{Results}

\subsection{Participating children}

One hundred and twenty-eight patients were eligible. Thirteen patients were excluded; five for being over 18 years at the date of inclusion and eight for being sufficient pancreatic CF. The number of children with data at different age groups in the remaining 115 children (42 PCD and 73 CF) is displayed in Figure 1. The median [IQR] duration of follow-up of patients was 2.3 [0.8;3.8] years. The median [IQR] number of blood gas measurements per child was 3 [2;4] and the median [IQR] delay between two measurements in a child was 13.1 [11.7;19.4] months.

The 42 PCD and 73 CF children were included at a similar age with characteristics at inclusion (cross-sectional study) displayed in Table 1. As expected, CF children were younger than PCD children at diagnosis due to neonatal screening. Frequency of 
bronchiectasis was similar between the two groups (61.9 \% in PCD versus 58.9\% in CF; $P=0.75$ ), but bronchiectasis was diagnosed at a younger age in PCD. Despite the later onset of bronchiectasis in CF children, Pseudomonas aeruginosa (P. aeruginosa) was more frequently detected in CF than in PCD children.

3.2. Comparison of lung function measurements at inclusion (cross-sectional study)

At time of inclusion, measured LF indexes were similar between the two groups except for static volumes in a sub-group of 16 (38\%) and 25 (34\%) of PCD and CF children; respectively (more hyperinflation in PCD group) (Table 2). In particular, $\mathrm{PaO}_{2}$ and $\mathrm{PaCO}_{2}$ were similar in PCD compared to CF children (median [IQR] -1.80 [-3.40; -0.40$]$ versus -1.80 [-4.20;0.60], $P=0.72$ and $0.20[-0.20 ; 0.60]$ versus 0.40 [0.00; 0.60], $P=0.15$; respectively).

3.3. Comparison of lung function measurements at follow-up (longitudinal study)

In all study children, increasing age was associated with a decrease in $\mathrm{PaO}_{2}$, $\mathrm{FEV}_{1}, \mathrm{FEF}_{25-75 \%}$ and $\mathrm{FEV}_{1} / \mathrm{FVC}$ but with an increase in $\mathrm{PaCO}_{2}$, (Figures 2a, 2b, 2d, E1). The change per year was significant with $ß$ coefficients [95\%CI] of $-0.21[-0.29$;0.13] z-score for $\mathrm{PaO}_{2}(P<0.0001), 0.06$ [0.04;0.08] z-score for $\mathrm{PaCO}_{2}(P<0.0001)$, 0.15 [-0.22;-0.09] z-score for $\mathrm{FEV}_{1}(P<0.0001)$, and -0.09 [-0.13;-0.05] z-score for $\mathrm{FEV}_{1} / \mathrm{FVC}$ (all $\left.P<0.0001\right)$.

$\mathrm{PaCO}_{2}$ was within the range of normal in all samples, except for three measurements performed in one CF teenager (Figure 2b). $\mathrm{PaCO}_{2}$ slowly increased with age in both diseases but with a gentler slope in PCD compared to CF children (ß 
coefficients [95\%CI] -0.22 [-0.42;-0.03]; $P=0.02$ ). Among the 107 children who fitted the mixed model for the $\mathrm{PaO}_{2}-\mathrm{PaCO}_{2}$ ratio (calculated from raw $\mathrm{PaO}_{2}$ and $\mathrm{PaCO}_{2}$ values), no significant effect of disease on $\mathrm{PaO}_{2}-\mathrm{PaCO}_{2}$ ratio progression was evidenced $(P=0.07)$ (Figure 2c).

In 60 CF children with identified mutations and a longitudinal follow-up of $\mathrm{PaO}_{2}$ and $\mathrm{PaCO}_{2}$, different $C F T R$ genotypes (classified into 5 classes according to the type of mutations: inframe/inframe [F508del/ F508del], $n=27$; inframe [F508del]/nonsense, $\quad \mathrm{n}=7$; $\quad$ inframe $\quad$ [F508del]/frameshift, $\mathrm{n}=13 ; \quad$ [nonF508del]/frameshift, $n=4$; inframe [F508del]/splicesite, $n=9$ ) were not associated with $\mathrm{PaO}_{2}(P=0.62)$ or with $\mathrm{PaCO}_{2}(P=0.16)$. Among the $21 \mathrm{PCD}$ children with genetic diagnosis, 11 different genes were involved preventing any statistical analysis in such small groups of children.

Variables associated with $\mathrm{PaO}_{2}$ in bivariate analyses were spirometry indexes (FVC, $\mathrm{FEV}_{1}, \mathrm{FEV}_{1} / \mathrm{FVC}, \mathrm{FEF}_{25 \%-75 \%}$ ) (241 observations in 99 children), but not disease, sex, or BMI (278 observations in 110 children) (Table 3). In multivariates models (241 observations in 99 children) (Table 4), $\mathrm{PaO}_{2}$ was independently associated with forced volumes $\left(0.65\right.$ [0.44;0.85] and 0.71 [0.44;0.97] $\mathrm{PaO}_{2} \mathrm{z}$-score increase for $1 \mathrm{z}$ score increase in FVC or $\mathrm{FEV}_{1}$, respectively; $P<0.0001$ ) but not with forced expiratory flows $(P>0.35)$. Moreover, $\mathrm{FEV}_{1} / \mathrm{FVC}$ was associated with $\mathrm{PaO}_{2}$ only in the model including FVC $\left(0.82[0.43 ; 1.21] \mathrm{PaO}_{2}\right.$ z-score increase for 1 z-score increase in $\left.\mathrm{FEV}_{1} / \mathrm{FVC} ; P<0.0001\right)($ Table 4).

\section{Discussion}

The present monocentric study in PCD and pancreatic insufficient CF children showed that 1 ) unlike we hypothesized, $\mathrm{PaO}_{2}$ could be measured low as early as 10 
years of age and significantly decreased over time in all studied children, irrespectively of the disease; 2) as expected, if gas exchange could reflect ventilationperfusion ratio mismatch, CF children worsened their gas exchange with age to a greater extent than PCD children, but exhibited (usually) no hypercapnia or $\mathrm{PaO}_{2}$ $\mathrm{PaCO}_{2}$ ratios dissimilar to that of PCD children 3) in line with previous studies, lung spirometry did not differ according to disease during childhood and was associated to $\mathrm{PaO}_{2}$ impairment.

\section{1. $\mathrm{PaO}_{2}$ and $\mathrm{PaCO}_{2}$ measurements}

No study has so far reported $\mathrm{PaO}_{2}$ and $\mathrm{PaCO}_{2}$ measurements in a large population of PCD patients and no previous authors have compared $\mathrm{PaO}_{2}$ or $\mathrm{PaCO}_{2}$ between PCD and CF patients. In the two diseases, $\mathrm{PaO}_{2}$ decrease progresses with ventilation-toperfusion inequality, mostly because of ventilation inhomogeneity. The initial location of lung impairment (basal in PCD and apical in CF) (Cohen-Cymberknoh et al., 2014) but also the possible poor lung perfusion due to low level of NO (lower in PCD) (Lundberg et al., 1996b, Walker et al., 2013) could involve differences between PCD and CF children’s gas exchange.

While the decrease in $\mathrm{PaO}_{2}$ can initially easily be compensated by an increase in ventilation in both groups, the steeper increase in $\mathrm{PaCO}_{2}$ in $\mathrm{CF}$ children could reflect the impairment of new territories with better ventilation-perfusion ratio (lower lobes) while upper lesions persist, preventing effective hyperventilation to keep steady the $\mathrm{PaCO}_{2}$ level. We do not know much of the progression with age of lung levels of NO except that the lower NO output measured in PCD compared to CF patients persisted from childhood to adulthood (Walker et al., 2013, Horvàth et al., 2003) in favour of a stable effect.

As previously shown (Kraemer et al., 2009), we measured a progressive increase in 
$\mathrm{PaCO}_{2}$ in CF children with nearly no measurement outside the range of normal while PCD children significantly less increased their $\mathrm{PaCO}_{2}$ (Magnin at al., 2012). In accordance with predicted changes in $\mathrm{PaO}_{2}$ and $\mathrm{PaCO}_{2}$ when ventilation-perfusion ratio decreases because of increasing ventilation inhomogeneity and in the absence of compensation from other lung territories (West, 2005), we measured a decrease in $\mathrm{PaO}_{2}$ much larger than the increase in $\mathrm{PaCO}_{2}$ (3.5 times more) resulting in no clear difference in the $\mathrm{PaO}_{2}-\mathrm{PaCO}_{2}$ ratio progression with age (Figure 2c) between the two groups.

Kraemer et al. measured different courses of $\mathrm{PaCO}_{2}$ values in a large cohort of $\mathrm{CF}$ children (Kraemer et al., 2009) according to the children's CFTR genotypes. We did not replicate this result, but the analysis of small groups probably lacked power. Moreover, the exclusion in our study of pancreatic sufficient patients may not totally explain this difference and Kraemer et al. might have included children with more severe phenotypes.

In our study children, only $\mathrm{PaO}_{2}$ could reach values lower than the lower limit of normal in patients as young as 10 years of age, and this decrease was associated with the decrease in forced expiratory volumes. The assessment of gas mixing demonstrated that ventilation inhomogeneity can occur with or without central airway obstruction in PCD and CF children (Aurora et al., 2005, Boon et al., 2015, Green et al., 2012, Gustafsson et al., 2003, Kraemer et al., 2005). The complexity of the relationships between infections, inflammation, and peripheral airway impairment in PCD and CF (Ratjen et al., 2016, Simpson et al., 2015) cannot be addressed from our retrospective study, but we acknowledge that despite possible more peripheral lung impairment in PCD children at inclusion (more lung hyperinflation with similar spirometry), no difference in $\mathrm{PaO}_{2}$ or $\mathrm{PaCO}_{2}$ values between the two groups of 
children was evidenced in our study. The magnitude of the recorded $\mathrm{PaO}_{2}$ decline (mean -0.21 z-score per year) was slightly higher than the one we previously found in PCD children (mean -0.17 z-score) (Magnin et al., 2012) or than that measured in a population of CF children (-0.83 mmHg/year) (Kraemer et al., 2009).

\subsection{Spirometry measurements}

The scarce studies that compared spirometry between PCD and CF children focused on FEV1, neglecting expiratory flows. FEV 1 was similar in PCD and CF children and adults tested during routine assessment (Cohen-Cymberknoh et al., 2014) or in PCD and CF children tested during a respiratory exacerbation (with a similar $\mathrm{FEV}_{1}$ decrease from baseline) (Ratjen et al., 2016). However, the general acceptation that respiratory prognosis is worse in CF patients seems to be contradicted by the absence of difference in spirometry during childhood, unless a slower decline with age were demonstrated in PCD patients which we did not find (Figures 2d, E1). Conversely, Cohen-Cymberknoh and colleagues (Cohen-Cymberknoh et al., 2014) were able to measure a large and significant decline in $\mathrm{FEV}_{1}$ over time in children and adults CF patients with or without pancreatic insufficiency, but not in PCD patients. The inclusion of adult patients might be responsible for the dissimilar

relationships between disease and $\mathrm{FEV}_{1}$ decrease. Moreover, the indisputable improvement in $\mathrm{FEV}_{1}$ in CF French children during the study (+ 15\% predicted at 10 14 years of age between 1995 and 2015) might have lessened the difference with PCD children (Vaincre la Mucoviscidose, 2017).

\subsection{Clinical differences between PCD and CF children}

The earlier age at bronchiectasis diagnosis in PCD compared to CF was unexpected. The age of bronchiectasis was reliable in CF children followed up since birth with a Computed Tomography no later than in the fifth years of age, i.e. before 
the median age at bronchiectasis diagnosis (Table 1). In PCD children, the delay between PCD and bronchiectasis diagnoses was shorter, probably because most of children diagnosed at a young age with PCD displayed unusual severe respiratory symptoms which required full work-up including lung imaging. Moreover, the finding of bronchiectasis in a child with a sino-pulmonary syndrome is highly suggestive of PCD after the exclusion of CF or other rare diseases. This procedure favours the diagnosis of young PCD children with bronchiectasis compared to PCD patients with no or less pulmonary symptoms (no early bronchiectasis), who are usually diagnosed later (except for subjects with situs inversus).

Despite similar proportions of bronchiectasis, $P$. aeruginosa was scarcely detected in PCD compared to CF children's sputum. The frequency of $P$. aeruginosa in PCD children (14.6\%) was comparable (11.1 to 14.2\%) (Green et al., 2012, Ratjen et al., 2016) or less (27\% and 37\%) (Maglione et al., 2014, Pifferi et al., 2012) than previously reported. In children and adults with PCD or CF, it was evidenced that $P$. aeruginosa in sputum was related to pulmonary hyperinflation and ventilation inhomogeneity (Kraemer et al., 2005, Pifferi et al., 2012), which was not confirmed for ventilation inhomogeneity in a study that included PCD patients, 89.9\% of whom did not have P. aeruginosa in sputum (Green et al., 2012). Differences in airway inflammation responses after bronchial infection between PCD and CF patients (Ratjen et al., 2016) may result in different impacts of infection on LF, but our study did not encompass enough PCD children with $P$. aeruginosa in sputum to look for this effect.

\subsection{Limits of the method}

Our study presents limitations mostly due to its retrospective design which in return allowed the analysis of repeated $\mathrm{PaO}_{2}$ and $\mathrm{PaCO}_{2}$ measurements during a long period. 
We did not compare arterial and capillary $\mathrm{PaO}_{2}$. A good correlation was found between arterial and capillary $\mathrm{PaO}_{2}$ in 70 sick children breathing air room (mean (SD) difference of 1.5 (0.5) mmHg) (Gaultier et al., 1979), and a meta-analysis including 664 individuals also measured a small difference between arterial and earlobe capillary $\mathrm{PaO}_{2}$ (mean [95\%CI] 2.40 [1.90;2.80] mmHg) (Zavorsky et al., 2007).

We did not calculate the alveolar-arterial $\mathrm{PO}_{2}$ difference; however, to take into account $\mathrm{PaCO}_{2}$ progression with respect to $\mathrm{PO}_{2}$ changes (Kraemer et al., 2009) we considered the $\mathrm{PaO}_{2}-\mathrm{PaCO}_{2}$ ratio which was not different between the two groups. The main limitation was the lack of direct evaluation of the ventilation to perfusion ratio which was not routine in the follow-up of children. Now days, ventilation inhomogeneity can non-invasively be tracked from early childhood using techniques such as the multiple breath washout, but routine evaluation of perfusion remains an issue in children.

Other factors influencing lung function were not taken into account (clinical status and treatment). However, except for age at bronchiectasis diagnosis (see comment in paragraph 4.3), most of clinical factors that significantly differed between groups (Table 1) were disease-specific (age at diagnosis, neonatal respiratory distress, otorhinolaryngological surgery) (De Boeck et al., 2017, Noone et al., 2004, PruliereEscabasse et al., 2010), and had, therefore, a potential effect on gas exchange included in disease status. Other factors were not mentioned such as the onset of allergic broncho-pulmonary aspergillosis (ABPA) which may have happened in some CF children but in none of the PCD children, leaving this infection also disease-related. Finally, treatments were not mentioned but they are also disease-related in France. For example, rhDNase would only be used in CF patients, topical steroids only in some PCD children and all children would perform physiotherapy. Therefore, looking at 
differences between PCD and CF children regarding these factors would be close to compare the single effect of the diseases.

\section{Conclusion}

This is the first study aimed at deciphering the potential differences in lung impairment between PCD and CF children using gas exchanges characteristics as an indirect reflect of ventilation/perfusion mismatch. Despite differences in pathophysiology, $\mathrm{PaO}_{2}$ was similarly impaired in both groups, but CF children may alter more their gas exchanges with time. Consequently, PCD children who deteriorate less with age might truly benefit from an early diagnosis to prevent early lung impairment. Further prospective studies including older patients and more direct measurements of ventilation-perfusion ratio might give insight into the different courses of these two diseases.

\section{Conflicts of interest: none}

Acknowledgments: We are grateful to Michèle Boulé, Houda Guillo, Marc Koskas, Marie-Claude La Rocca, Lucia Maingot, and Noria Medjahdi for their help in supervising the children's lung function tests and to Claire Goaguen, Pascale Jacquemart, Valérie Le Bail, Isabelle Schmit, and Françoise Vallée for technical assistance (all working in Unité d’Exploration Fonctionnelle Respiratoire, Hôpital Armand-Trousseau, Paris, France). We gratefully acknowledge the help of Julie Bernard and Damir Mohamed (Unité d’Epidemiologie Clinique, Assistance PubliqueHôpitaux de Paris, CHU Robert Debré, Paris, France) with data management and statistical analysis. We thank Evan Knight for helping with the language. 


\section{References}

Aurora P., Bush A., Gustafsson P., Oliver C., Wallis C., Price J., Stroobant J., Carr S., Stocks J., 2005. Multiple-breath washout as a marker of lung disease in preschool children with cystic fibrosis. Am J Respir Crit Care Med. 171: 249-256.

Beydon N., Davis S.D., Lombardi E., Allen J.L., Arets H.G., Aurora P., Bisgaard H., Davis G.M., Ducharme F.M., Eigen H., Gappa M., Gaultier C., Gustafsson P.M., Hall G.L., Hantos Z., Healy M.J., Jones M.H., Klug B., Lodrup Carlsen K.C., McKenzie S.A., Marchal F., Mayer O.H., Merkus P.J., Morris M.G., Oostveen E., Pillow J.J., Seddon P.C., Silverman M., Sly P.D., Stocks J., et al., 2007. An official American Thoracic Society/European Respiratory Society statement: pulmonary function testing in preschool children. Am J Respir Crit Care Med. 175: 1304-1345.

Boon M., Vermeulen F.L., Gysemans W., Proesmans M., Jorissen M., De Boeck K., 2015. Lung structure-function correlation in patients with primary ciliary dyskinesia. Thorax. 70: 339-345.

Cohen-Cymberknoh M., Simanovsky N., Hiller N., Gileles H.A., Shoseyov D., Kerem E., 2014. Differences in disease expression between primary ciliary dyskinesia and cystic fibrosis with and without pancreatic insufficiency. Chest. 145: 738-744.

De Boeck K., Munck A., de Monestrol I., Gulmans V., Lemonnier L., Middleton P.G., Wanyama S., Thomas M.. 2017. Does newborn screening influence the young cystic fibrosis cohort included in national registries? Eur Respir J. 49: 1600686. 
Ellerman A. and Bisgaard H., 1997. Longitudinal study of lung function in a cohort of primary ciliary dyskinesia. Eur Respir J. 10: 2376-2379.

Gaultier C., Boule M., Allaire Y., Clement A., Buvry A., Girard F., 1979.

Determination of capillary oxygen tension in infants and children: assessment of methodology and normal values during growth. Bull Eur Physiopathol Respir. 14: 287-297.

Green K., Buchvald F.F., Marthin J.K., Hanel B., Gustafsson P.M., Nielsen K.G., 2012. Ventilation inhomogeneity in children with primary ciliary dyskinesia. Thorax. 67: 49-53.

Gustafsson P.M., Aurora P., Lindblad A., 2003. Evaluation of ventilation maldistribution as an early indicator of lung disease in children with cystic fibrosis. Eur Respir J. 22: 972-979.

Hellinckx J., Demedts M., De Boeck K., 1998. Primary ciliary dyskinesia: evolution of pulmonary function. Eur J Pediatr. 157: 422-426.

Horváth I., Loukides S., Wodehouse T., Csiszér E., Cole P.J., Kharitonov S.A., Barnes P.J., 2003. Comparison of exhaled and nasal nitric oxide and exhaled carbon monoxide levels in bronchiectatic patients with and without primary ciliary dyskinesia. Thorax. 58:68-72.

Irving S.J., Ives A., Davies G., Donovan J., Edey A.J., Gill S.S., Nair A., Saunders C., Wijesekera N.T., Alton E.W., Hansell D., Hogg C., Davies J.C., Bush A., 2013. Lung clearance index and high-resolution computed tomography scores in primary ciliary dyskinesia. Am J Respir Crit Care Med. 188: 545-549. 
Kerem E., Viviani L., Zolin A., MacNeill S., Hatziagorou E., Ellemunter H., Drevinek P., Gulmans V., Krivec U., Olesen H., 2014. Factors associated with FEV1 decline in cystic fibrosis: analysis of the ECFS patient registry. Eur Respir J. 43: $125-133$.

Knowles M.R. and Boucher R.C., 2002. Mucus clearance as a primary innate defense mechanism for mammalian airways. Journal of Clinical Investigation. 109: 571577.

Konstan M.W., Morgan W.J., Butler S.M., Pasta D.J., Craib M.L., Silva S.J., Stokes D.C., Wohl M.E., Wagener J.S., Regelmann W.E., Johnson C.A., 2007. Risk factors for rate of decline in forced expiratory volume in one second in children and adolescents with cystic fibrosis. J Pediatr. 151: 134-139.

Kraemer R., Blum A., Schibler A., Ammann R.A., Gallati S., 2005. Ventilation inhomogeneities in relation to standard lung function in patients with cystic fibrosis. Am J Respir Crit Care Med. 171: 371-378.

Kraemer R., Baldwin D.N., Ammann R.A., Frey U., Gallati S., 2006. Progression of pulmonary hyperinflation and trapped gas associated with genetic and environmental factors in children with cystic fibrosis. Respir Res.7: 138.

Kraemer R., Latzin P., Pramana I., Ballinari P., Gallati S., Frey U., 2009. Long-term gas exchange characteristics as markers of deterioration in patients with cystic fibrosis. Respir Res. 10: 106.

Liou TG., Adler FR., FitzSimmons SC., Cahill BC., Hibbs JR., Marshall BC., 2001. Predictive 5-Year Survivorship Model of Cystic Fibrosis. Am J Epidemiol. 153: 345-352. 
Lundberg J.O.N., Weitzberg E., Lundberg J.M., Alving K., 1996a. Nitric oxide in exhaled air. Eur Respir J. 9: 2671-2680.

Lundberg J.O.N., Settergren G., Gelinder S., Lundberg J.M., Alving K. Weitzberg E., 1996b. Inhalation of nasally derived nitric oxide modulates pulmonary function in humans. Acta Physiol Scand. 158:343-347.

Maglione M., Bush A., Nielsen K.G., Hogg C., Montella S., Marthin J.K., Di Giorgio A., Santamaria F., 2014. Multicenter analysis of body mass index, lung function, and sputum microbiology in primary ciliary dyskinesia. Pediatr Pulmonol. 49: $1243-1250$.

Magnin M.L., Cros P., Beydon N., Mahloul M., Tamalet A., Escudier E., Clement A., Le Pointe H.D., Blanchon S., 2012. Longitudinal lung function and structural changes in children with primary ciliary dyskinesia. Pediatr Pulmonol. 47: 816825.

Marthin J.K., Petersen N., Skovgaard L.T., Nielsen K.G., 2010. Lung function in patients with primary ciliary dyskinesia: a cross-sectional and 3-decade longitudinal study. Am J Respir Crit Care Med. 181: 1262-1268.

Marthin J.K., Nielsen K.G., 2011. Choice of nasal nitric oxide technique as first-line test for primary ciliary dyskinesia. Eur Respir J. 37: 559-565.

Miller M.R., Hankinson J., Brusasco V., Burgos F., Casaburi R., Coates A., Crapo R., Enright P., van der Grinten C.P., Gustafsson P., Jensen R., Johnson D.C., MacIntyre N., McKay R., Navajas D., Pedersen O.F., Pellegrino R., Viegi G., Wanger J., 2005. Standardisation of spirometry. Eur Respir J. 26: 319-338. 
Noone P.G., Leigh M.W., Sannuti A., Minnix S.L., Carson J.L., Hazucha M., Zariwala M.A., Knowles M.R., 2004. Primary ciliary dyskinesia: diagnostic and phenotypic features. Am J Respir Crit Care Med. 169: 459-467.

Pifferi M., Bush A., Pioggia G., Caramella D., Tartarisco G., Di C.M., Zangani M., Chinellato I., Maggi F., Tezza G., Macchia P., Boner A., 2012. Evaluation of pulmonary disease using static lung volumes in primary ciliary dyskinesia. Thorax. 67: 993-999.

Pruliere-Escabasse V., Coste A., Chauvin P., Fauroux B., Tamalet A., Garabedian E.N., Escudier E., Roger G., 2010. Otologic features in children with primary ciliary dyskinesia. Arch Otolaryngol Head Neck Surg. 136: 1121-1126.

Quanjer P.H., Stanojevic S., Cole T.J., Baur X., Hall G.L., Culver B.H., Enright P.L., Hankinson J.L., Ip M.S.M., Zheng J., Stocks J., the ERS Global Lung Function Initiative., 2012. Multi-ethnic reference values for spirometry for the 3-95-yr age range: the global lung function 2012 equations. Eur Respir J. 40: 1324-1343.

Ratjen F., Waters V., Klingel M., McDonald N., Dell S., Leahy T.R., Yau Y., Grasemann H., 2016. Changes in airway inflammation during pulmonary exacerbations in patients with cystic fibrosis and primary ciliary dyskinesia. Eur Respir J. 47: 829-836.

Ren C.L., Pasta D.J., Rasouliyan L., Wagener J.S., Konstan M.W., Morgan W.J., 2008. Relationship between inhaled corticosteroid therapy and rate of lung function decline in children with cystic fibrosis. J Pediatr. 153: 746-751. 
Rolland-Cachera M.F., Cole T.J., Sempé M., Tichet J., Rossignol C., Charraud A., 1991. Body Mass Index variations: centiles from birth to 87 years. Eur J Clin Nutr. 45: 13-21.

Stocks J., Quanjer PH., 1995. Reference values for residual volume, functional residual capacity and total lung capacity. ATS Workshop on Lung Volume Measurements. Official Statement of The European Respiratory Society. Eur Respir J. 8: 492-506.

Simpson S.J., Ranganathan S., Park J., Turkovic L., Robins-Browne R.M., Skoric B., Ramsey K.A., Rosenow T., Banton G.L., Berry L., Stick S.M., Hall G.L., 2015. Progressive ventilation inhomogeneity in infants with cystic fibrosis after pulmonary infection. Eur Respir J. 46: 1680-1690.

Vaincre la Mucoviscidose and Institut National d’Études Démographiques (Ined). French Cystic Fibrosis Registry. Annual data report 2015, Paris, May 2017. http://www.vaincrelamuco.org/sites/default/files/french_cf_patient_registry_2015 .pdf (accessed 27 November 2017).

Walker W.T., Liew A., Harris A., Cole J., Lucas J.S., 2013. Upper and lower airway nitric oxide levels in primary ciliary dyskinesia, cystic fibrosis and asthma. Respir Med. 107: 380-386.

Wanger J., Clausen J.L., Coates A., Pedersen O.F., Brusasco V., Burgos F., Casaburi R., Crapo R., Enright P., van der Grinten C.P., Gustafsson P., Hankinson J., Jensen R., Johnson D., MacIntyre N., McKay R., Miller M.R., Navajas D., Pellegrino R., Viegi G. 2005. Standardisation of the measurement of lung volumes. Eur Respir J. 26: 511-522. 
West J.B., 2005. Ventilation-perfusion relationships. In Respiratory physiology. The essentials, West J.B. $7^{\text {th }}$ Eds. Lippincott Williams \& Wilkins, Baltimore, pp. 5572.

Zavorsky G.S., Cao J., Mayo N.E., Gabbay R., Murias J.M., 2007. Arterial versus capillary blood gases: a meta-analysis. Respir Physiol Neurobiol. 155: 268-279. 


\section{Figures legends}

Figure 1 - Number of children with $\mathrm{PaO}_{2}$ measurements at different age groups

Closed bars represent PCD children and open bars CF children

Figure 2 - Gas exchanges and spirometry trends over time in children with Primary Ciliary Dyskinesia or Cystic Fibrosis

2a: $\mathrm{PaO}_{2}$ in children with Primary Ciliary Dyskinesia (PCD) (closed circles) and Cystic Fibrosis (CF) (open circles)

2b: $\mathrm{PaCO}_{2}$ in PCD (closed circles) and CF (open circles) children

2c: $\mathrm{PaO}_{2}-\mathrm{PaCO}_{2}$ ratio in PCD (closed circles) and CF (open circles) children

2d: FEV 1 / FVC in PCD (closed circles) and CF (open circles) children

Solid lines are linear regressions over time in PCD children, dotted lines are linear regressions over time in CF children. Each child contributed for more than one point.

$\mathrm{PaO}_{2}$ : partial pressure of Oxygen; $\mathrm{PaCO}_{2}$ : partial pressure of Carbon Dioxide; FVC:

Forced Vital Capacity; FEV 1 : Forced Expiratory Volume in 1 second 


\section{Tables}

Table 1 - Characteristics of children at inclusion

\begin{tabular}{|c|c|c|c|}
\hline & $\begin{array}{c}\text { PCD } \\
\text { n=42 unless } \\
\text { specified } \\
\end{array}$ & $\begin{array}{c}\text { CF } \\
\text { n=73 unless } \\
\text { specified } \\
\end{array}$ & $P$ value \\
\hline Female & $22(52.4)$ & $34(46.6)$ & $=0.55$ \\
\hline $\begin{array}{l}\text { Geographical origin } \\
\text { Europe } \\
\text { Sub-Saharan Africa } \\
\text { Others }\end{array}$ & $\begin{array}{c}37(88.1) \\
3(7.1) \\
2(4.8)\end{array}$ & $\begin{array}{c}\mathrm{n}=72 \\
66(91.6) \\
2(2.8) \\
4(5.6)\end{array}$ & $=0.62$ \\
\hline Neonatal respiratory distress & $\begin{array}{c}n=33 \\
23(69.7)\end{array}$ & $\begin{array}{l}\mathrm{n}=66 \\
1(1.5)\end{array}$ & $<0.0001$ \\
\hline Age at diagnosis (years) & $6.7[3.1 ; 10.1]$ & $\begin{array}{c}n=57 \\
0.4[0.1 ; 2.0]\end{array}$ & $<0.0001$ \\
\hline Age at inclusion (years) & $8.9[6.4 ; 13.5]$ & $11.0[7.3 ; 14.2]$ & $=0.23$ \\
\hline BMI (z-score) & $-0.38[-1.07 ; 0.41]$ & $-0.48[-1.15 ; 0.27]$ & $=0.99$ \\
\hline Otorhinolaryngology surgery & $\begin{array}{c}n=40 \\
14(35)\end{array}$ & $\begin{array}{c}\mathrm{n}=71 \\
5(7.0)\end{array}$ & $=0.0002$ \\
\hline $\begin{array}{l}\text { Type of surgery } \\
\text { Adeno and/or tonsillectomy } \\
\text { Myringotomy } \\
\text { Other }\end{array}$ & $\begin{array}{c}\mathrm{n}=14 \\
5(35.7) \\
8(57.1) \\
1(7.1) \\
\end{array}$ & $\begin{array}{c}n=5 \\
2(40.0) \\
0(0.0) \\
3(60.0) \\
\end{array}$ & \\
\hline Bronchiectasis & 26 (61.9) & 43 (58.9) & $=0.75$ \\
\hline $\begin{array}{l}\text { Age at bronchiectasis diagnosis } \\
\text { (years) }\end{array}$ & $\begin{array}{c}n=19 \\
8.0[5.0 ; 10.8]\end{array}$ & $\begin{array}{c}\mathrm{n}=38 \\
10.2[8.0 ; 12.0]\end{array}$ & $=0.01$ \\
\hline $\begin{array}{l}\text { Pseudomonas aeruginosa in sputum } \\
\text { (ever) }\end{array}$ & $\begin{array}{c}n=41 \\
6(14.6)\end{array}$ & 48 (59.3) & $<0.0001$ \\
\hline
\end{tabular}

Results are expressed as number (percentage) or as median [Interquartile Range; IQR]

PCD: Primary Ciliary Dyskinesia; CF: Cystic Fibrosis; BMI: Body Mass Index; 
Table 2 - Lung function of the study children at inclusion

\begin{tabular}{lccc}
\hline $\begin{array}{l}\text { Indexes } \\
\text { median [IQR] }\end{array}$ & PCD & $\mathbf{C F}$ & $P$ value \\
\hline $\mathrm{PaO}_{2}$ (z-score) & $\mathrm{n}=42$ & $\mathrm{n}=73$ & $=0.72$ \\
& $-1.80[-3.40 ;-0.40]$ & $-1.80[-4.20 ; 0.60]$ & \\
\hline $\mathrm{PaCO}_{2}$ (z-score) & $\mathrm{n}=42$ & $\mathrm{n}=73$ & $=0.15$ \\
& $0.20[-0.20 ; 0.60]$ & $0.40[0.00 ; 0.60]$ & \\
\hline $\mathrm{FEV}_{1}$ (z-score) & $\mathrm{n}=27$ & $\mathrm{n}=59$ & $=0.12$ \\
& $-1.21[-1.82 ;-0.39]$ & $-1.82[-3.05 ;-0.29]$ & \\
\hline FEV 1 /FVC (z-score) & $\mathrm{n}=27$ & $\mathrm{n}=59$ & $=0.14$ \\
& $-1.33[-1.60 ;-0.25]$ & $-1.38[-2.13 ;-0.64]$ & \\
\hline $\mathrm{RV}$ (\% predicted) & $\mathrm{n}=16$ & $\mathrm{n}=25$ & $=0.10$ \\
& $132.9[110.1 ; 162.1]$ & $118.6[101.7 ; 158.9]$ & \\
\hline $\mathrm{RV} / \mathrm{TLC}$ (\% predicted) & $\mathrm{n}=16$ & $\mathrm{n}=25$ & $=\mathbf{0 . 0 1}$ \\
& $130.1[112.8 ; 141.2]$ & $116.6[97.3 ; 145.9]$ & \\
\hline $\mathrm{TLC}$ (\% predicted) & $\mathrm{n}=18$ & $\mathrm{n}=31$ & $=0.25$ \\
& $105.0[92.51 ; 116.2]$ & $107.1[99.7 ; 113.7]$ & \\
\hline
\end{tabular}

$\mathrm{PaO}_{2}$ : partial pressure of $\mathrm{O}_{2} ; \mathrm{PaO}_{2}$ : partial pressure of $\mathrm{CO}_{2} ; \mathrm{FVC}$ : Forced Vital Capacity; FEV 1 : Forced Expiratory Volume in 1 second; RV: Residual Volume; TLC: Total Lung Capacity; IQR: interquartile range 
Table 3 Association between covariates and $\mathrm{PaO}_{2}$ in crude models: Age adjusted bivariate mixed model constructed with 278 observations in $\mathbf{1 1 0}$ children for group disease, sex and BMI, and with 241 observations in 99 children for lung function indexes

\begin{tabular}{|c|c|c|c|}
\hline Covariates & Unit & $\beta[95 \% \mathrm{CI}]$ & $P$ value \\
\hline Age & year & $-0.22[-0.30 ;-0.15]$ & $<0.0001$ \\
\hline Groups & & & \\
\hline PCD & & $0.03[-0.45 ; 1.05]$ & $=0.43$ \\
\hline CF (reference) & & Ref & \\
\hline Age & year & $-0.21[-0.29 ;-0.13]$ & $<0.0001$ \\
\hline Sex & & & \\
\hline Female & & $-0.32[-1.02 ; 0.39]$ & $=0.38$ \\
\hline Male (reference) & & Ref & \\
\hline Age & year & $-0.22[-0.29 ;-0.14]$ & $<0.0001$ \\
\hline BMI & & & $=0.52$ \\
\hline BMI>2 z-score & & $0.66[-1.07 ; 2.39]$ & \\
\hline$-2<$ BMI $<+2$ z-score & & $0.59[-0.44 ; 1.61]$ & \\
\hline$<-2$ z-score (reference) & & Ref & \\
\hline Age & year & $-0.22[-0.29 ;-0.14]$ & $<0.0001$ \\
\hline FEV 1 & z-score & $0.77[0.61 ; 0.93]$ & $<0.0001$ \\
\hline Age & year & $-0.11[-0.19 ;-0.04]$ & 0.004 \\
\hline FVC & z-score & $0.71[0.53 ; 0.89]$ & $<0.0001$ \\
\hline Age & year & $-0.16[-0.24 ;-0.08]$ & $=0.0002$ \\
\hline FEV $1 /$ FVC & z-score & $0.85[0.61 ; 1.09]$ & $<0.0001$ \\
\hline Age & year & $-0.16[-0.24 ;-0.08]$ & $=0.0001$ \\
\hline $\mathbf{F E F}_{25 \%-75 \%}$ & z-score & $0.62[0.46 ; 0.78]$ & $<0.0001$ \\
\hline Age & year & $-0.16[-0.23 ;-0.08]$ & $=0.0001$ \\
\hline
\end{tabular}

95\%CI: 95\% confidence interval; BMI: Body Mass Index; FEV ${ }_{1}$ : Forced Expiratory Volume in 1 second; FVC: Forced Vital Capacity; $\mathrm{FEF}_{25 \%}$-75\% : Mean Forced Expiratory Flows between $25 \%$ and $75 \%$ of FVC 
The beta coefficient indicates the amount of $\mathrm{PaO}_{2} \mathrm{z}$-score increase or decrease (positive or negative beta coefficient, respectively) compared to the reference group (=0) for categorical factors and for each 1 unit (1 year or $1 \mathrm{z}$-score) increase in continuous covariates. 
Table 4 -Association between covariates and $\mathrm{PaO}_{2}$ in multivariate models adjusted on group disease for 241 observations in 99 children

\begin{tabular}{|c|c|c|c|c|c|}
\hline \multirow[t]{2}{*}{ Covariates } & \multirow[t]{2}{*}{ Unit } & \multicolumn{2}{|c|}{ Model including FVC } & \multicolumn{2}{|c|}{ Model including FEV 1} \\
\hline & & $\beta[95 \% \mathrm{CI}]$ & $P$ value & $\beta[95 \% C I]$ & $P$ value \\
\hline Age & 1 year & $-0.11[-0.19 ;-0.04]$ & 0.003 & $-0.11[-0.19 ;-0.04]$ & 0.004 \\
\hline$\overline{F E V_{1}}$ & 1 z-score & - & & $0.71[0.44 ; 0.97]$ & $<0.0001$ \\
\hline FVC & 1 z-score & $0.65[0.44 ; 0.85]$ & $<0.0001$ & - & \\
\hline FEV $_{1} /$ FVC & 1 z-score & $0.82[0.43 ; 1.21]$ & $<0.0001$ & $0.29[-0.08 ; 0.65]$ & 0.13 \\
\hline $\mathbf{F E F}_{25 \%-75 \%}$ & 1 z-score & $-0.14[-0.44 ; 0.16]$ & 0.36 & $-0.08[-0.40 ; 0.22]$ & 0.58 \\
\hline
\end{tabular}

Multivariate models are adjusted for age and group. Two models were given because of colinearity of FVC and FEV 1 .

95\%CI: 95\% confidence interval. FVC: Forced Vital Capacity; FEV 1 : Forced Expiratory

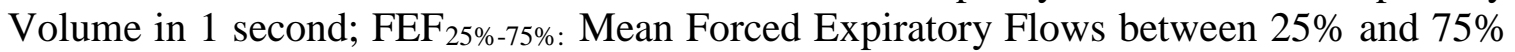
of FVC.

The beta coefficient indicates the amount of $\mathrm{PaO}_{2}$ z-score increase or decrease (positive or negative beta coefficient, respectively) for each 1 unit (1 year or 1 z-score) increase of the covariate 